\title{
MODEL PEMBELAJARAN PAKEM ( Pembelajaran, Aktif, Kreatif, Efektif, Menyenangkan )
}

\author{
Muhammad Ullil Fahri \\ muhammad.fahri001@binus.ac.id \\ https://ullilfahri.skb.ovh/
}

Rusman, 2014: 321 mengatakan bahwa: PAKEM adalah penerjemah dari empat pilar yang dirancang oleh UNESCO [1] :

1. belajar mengetahui, yaitu mempelajari ilmu pengetahuan yang berupa pembelajaran aspek kognitif,

2. learning to do, atau learning to do yang merupakan aspek praktek dan implementasi,

3. learning to be, yaitu belajar menjadi diri sendiri dalam bentuk aspek kepribadian dan kesesuaian dengan diri sendiri, anak ini juga sesuai dengan konsep Howard Gardner tentang "multiple intelligence"

4. belajar hidup bersama, yaitu belajar hidup bersama dalam bentuk aspek sosial anak, cara bersosialisasi dan cara hidup bertoleransi dalam keberagaman yang ada disekitar siswa.

Dari pendapat diatas model pembelajaran pakem memiliki 4 unsur inti. Unsur pertama fokus ke ranah kognitif. Aspek dari ranah kognitif harus bisa dilaksanakan agar membantu siswa. Berikut adalah aspek dari ranah kogniti [2] :

1. Pengetahuan / Hafalan / Ingatan

2. Pemahaman

3. Penerapan

4. Analisis

5. Sintesis

6. Penilaian / Penghargaan / Evaluasi

Pada pilar kedua fokus ke learning to do, yaitu siswa diberikan pengalaman secara langsung di lapangan agar dapat dilaksanakan oleh siswa. Dalam pengertian yang lebih singkat, belajar melakukan berarti belajar melakukan sesuatu. Sekolah sebagai forum komunitas belajar harus memfasilitasi peserta didik untuk mengaktualisasikan keterampilan, bakat dan minatnya sehingga "Learning to do" (belajar melakukan sesuatu) dapat terwujud. Meskipun bakat dan minat anak memang dipengaruhi oleh faktor keturunan, namun pertumbuhan dan perkembangan bakat dan minatnya juga bergantung pada lingkungan. Karena kita semua tahu bahwa keterampilan adalah alat untuk menopang kehidupan seseorang, bahkan keterampilan lebih dominan dari pada sekadar menguasai pengetahuan.[3]. Contoh learning to do pada mata pelajaran komputer, siswa di ajak secara langsung praktek penulisan dengan bantuan microsoft word.

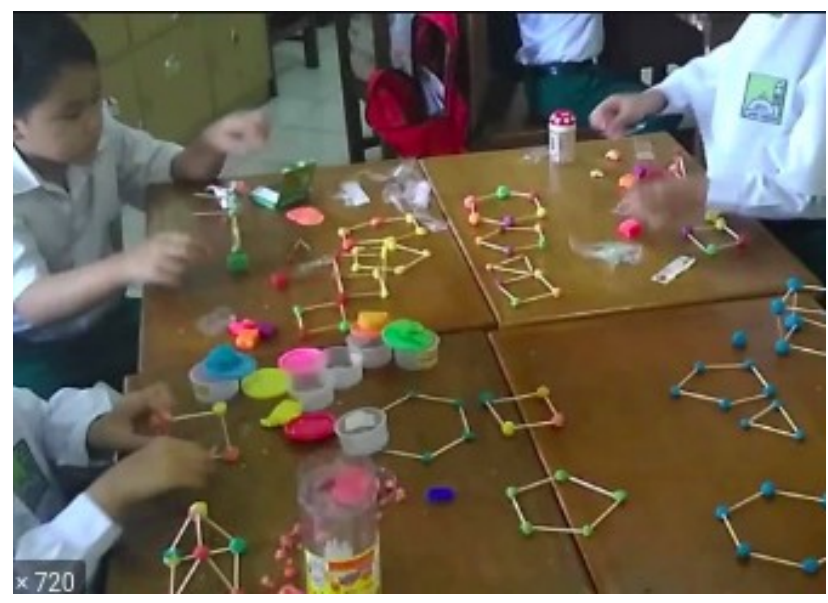

Gambar 1. Praktek Matematika SD [4]

Pada gambar 1 merupakan contoh praktek matematika pada anak SD. Dimana siswa diajak untuk mengenal bentuk secara langsung tentang bangun datar dan ruang dari tusuk gigi.

Pilar ketiga yang dibahas adalah learning to be yaitu belajar dari diri sendiri. Belajar untuk diartikan sebagai belajar melakukan sesuatu. Menjadi diri sendiri didefinisikan sebagai proses memahami kebutuhan dan identitas diri sendiri. Belajar bertingkah laku sesuai dengan norma dan kaidah yang berlaku di 
masyarakat, belajar menjadi orang sukses, sebenarnya merupakan proses pencapaian pemenuhan diri [3]. Maksud dari pendapat diatas adalah menjadi siswa kita dapat melakukan interaksi ke masyarakat dengan perilaku yang baik. Belajar menjadi berarti belajar berkembang sepenuhnya. Setelah siswa atau manusia belajar mengetahui, belajar bekerja, mereka pasti manusia seutuhnya. Dalam Learning to Be ini, manusia berperan sebagai makhluk individu dan juga sebagai makhluk sosial dalam masyarakat [5]. harapan dari learning to be adalah ketika siswa sudah mendapatkan pelajaran di sekolah maka siswa dapat memberikan solusi nyata ke masyarakat. Penerapan ilmu secara langsung di masyarakat. Multiple intelligence adalah yang dapat diartikan sebagai kemampuan seseorang dalam memecahkan suatu masalah[6]. Penerapan konsep pembelajaran menjadi tidak lepas dari konsep multiple intelligence dimana siswa harus mampu memecahkan masalah. Awalnya multiple intelligence diaktifkan hanya oleh 8 jenis kecerdasan, namun seiring berjalannya waktu dan pengetahuan, multiple intelligence menjadi 9 kecerdasan, yaitu [6] :

1. Kecerdasan linguistik: berarti kemampuan menggunakan kata-kata secara efektif baik secara lisan maupun tulisan.

2. Kecerdasan matematis-logis (kecerdasan logis-matematis): menunjukkan kemampuan relatif untuk menggunakan angka dan logika

3. Kecerdasan spasial: adalah kemampuan menangkap dunia visual ruang secara tepat dan juga mengenali bentuk dan objek dengan tepat.

4. Kecerdasan kinestetik-jasmani: adalah kemampuan untuk menggunakan tubuh dan gerak tubuh untuk mengungkapkan gagasan dan perasaan.

5. Kecerdasan musik: yaitu kemampuan mengembangkan, mengekspresikan dan menikmati bentuk musik dan suara, peka terhadap ritme, melodi dan intonasi, serta kemampuan memainkan alat musik.
6. Kecerdasan interpersonal: yaitu kemampuan untuk memahami dan peka terhadap perasaan, intensitas, motivasi, karakter, temperamen orang lain.

7. Kecerdasan intrapersonal: ini adalah kemampuan yang berhubungan dengan pengetahuan diri dan kemampuan untuk bertindak secara adaptif atas dasar pengalaman diri dan mampu untuk merefleksikan dan menyeimbangkan, kesadaran yang tinggi terhadap ide.

8. Kecerdasan naturalistik: yaitu kemampuan memahami flora dan fauna dengan baik, menikmati alam, mengenal tumbuhan dan hewan dengan baik.

9. Kecerdasan eksistensial: ini adalah kapasitas yang terkait dengan kepekaan dan kemampuan seseorang untuk menanggapi masalah terdalam dari keberadaan atau keberadaan manusia.

Pilar keempat yang learning to life together lebih ke aspek sosial. Hal ini dapat diartikan dengan menanamkan kesadaran kepada siswa untuk menjadi bagian dari kelompok masyarakat [7]. Dari pendapat diatas merupakan sugesti yang harus ditanamkan ke peserta didik sangat pentingnya berkelompok bersama masyarakat (sosialisasi). Pada pilar keempat ini, kebiasaan hidup bersama, saling menghargai, terbuka, memberi dan menerima perlu dikembangkan disekolah. Dengan kemampuan yang dimiliki siswa, mengikuti proses pembelajaran dapat dijadikan tolak ukur untuk dapat berperan dalam lingkungan dimana individu tersebut berada, sekaligus dapat memposisikan diri sesuai dengan perannya sendiri.[7].

Pakem yang merupakan singkatan dari pembelajaran aktif, kreatif, efektif, dan menyenangkan merupakan model pembelajaran kontekstual yang melibatkan setidaknya empat prinsip utama dalam proses pembelajaran. [8] .

1. Proses interaksi (siswa berinteraksi aktif dengan guru, sesama siswa, multimedia, referensi, lingkungan, dll).

2. Proses komunikasi mengkomunikasikan

(siswa pengalaman 
belajarnya dengan guru dan siswa lain melalui cerita, dialog atau simulasi).

3. Proses refleksi (siswa memikirkan kembali arti dari apa yang telah mereka pelajari dan apa yang telah mereka lakukan).

4. Proses eksplorasi (siswa mengalami secara langsung dengan melibatkan semua indera mereka melalui observasi, eksperimen, investigasi atau wawancara)

Ciri - ciri karakteristik dalam model pembelajaran PAKEM [8].

1. Belajar mengaktifkan siswa

2. Mendorong kreativitas siswa dan guru

3. Pembelajaran yang efektif

4. Belajar itu menyenangkan, terutama bagi siswa

Kelebihan dan kelemahan PAKEM dapat dijelaskan seperti berikut. Pertama penulis menyajikan kelebihan dari PAKEM [8] :

1. Perbedaan individu siswa tidak diperhitungkan, termasuk laki-laki / perempuan, cerdas / kurang cerdas, sosial, tingkat ekonomi tinggi / rendah

2. Belajar tidak mengajarkan kecakapan hidup

3. Pengelompokan siswa masih dalam hal pengaturan tempat duduk, aktivitas siswa seringkali tidak mencerminkan pembelajaran kooperatif yang sebenarnya

4. Guru tidak memiliki kesempatan untuk menyaksikan pembelajaran yang baik.

5. Pajangan sering menampilkan hasil karya siswa yang cenderung seragam

6. Pembelajaran seringkali berupa pengisian lembar kerja siswa (LKS) yang sebagian besar soal ditutup

Penerapan pendekatan dapat diikuti berdasarkan penelitian penerapan pembelajaran PAKEM dalam meningkatkan hasil belajar matematika, yang telah dilakukan [9]:

1. Pembelajaran dengan pendekatan / strategi PAKEM dapat meningkatkan hasil belajar. Hal ini dibuktikan dengan peningkatan hasil belajar yang diperoleh melalui tes dari 88,27 (siklus I) menjadi 97,59 (siklus II);

2. Suasana belajar yang menyenangkan dapat mendorong siswa untuk melakukan eksplorasi (eksplorasi) sehingga semua aspek emosional, kognitif dan sosial dapat berkembang dengan baik. Hal ini ditunjukkan dengan kegiatan yang dilakukan oleh siswa seperti keberanian bertanya, mengemukakan pendapat, bekerjasama dengan teman dan berkembang dengan baik;

3. Bermain untuk anak merupakan suatu kebutuhan, sehingga segala aktivitas dilakukan oleh anak jika memenuhi kebutuhannya. Dapat dikatakan bahwa pembelajaran dilakukan dengan cara bermain, sehingga dapat memenuhi kebutuhan anak;

4. Kegiatan pembelajaran yang memperhatikan semua aspek perkembangan anak (sosial, emosional, kognitif, motorik) yang terdapat pada diri anak, akan menghasilkan sesuatu yang bermakna bagi siswa, dan inilah kunci keberhasilannya;

5. Hasil belajar yang baik yang dicapai siswa tidak lepas dari minat belajarnya. Minat belajar timbul pada diri siswa apabila kebutuhan siswa dapat dipenuhi oleh suasana belajar yang diciptakan oleh guru. PAKEM dapat merangsang minat belajar matematika siswa

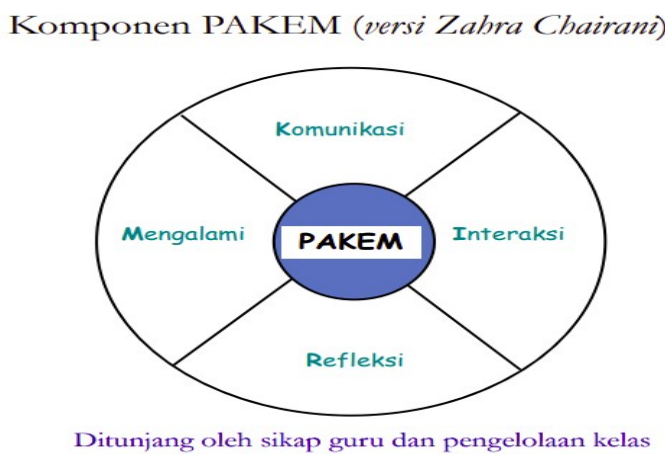

Gambar 2. Komponen PAKEM [10] 
Berikut penjelasan Komponen PAKEM [10] ? 1. Mengalami

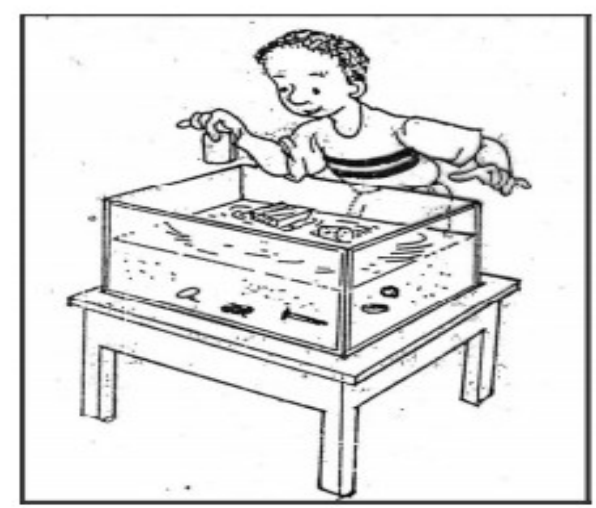

Gambar 3. Mengalami

Pada gambar 3 merupakan contoh dari siswa mengalami siswa interaksi pembelajaran secara langsung. Siswa melakukan pengamatan, melakukan percobaan, melakukan penyelidikan, dan melakukan wawancara. Dengan manfaat anak belajar banyak melalui berbuat secara langsung. Serta pengalaman langsung mengaktifkan banyak indera.

\section{Komunikasi}

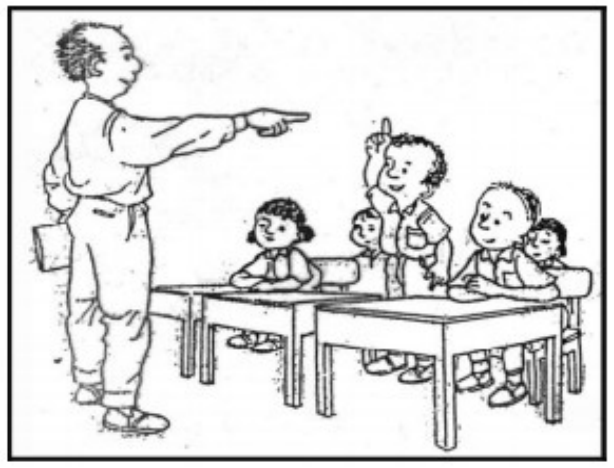

Gambar 4. Komunikasi

Pada gambar merupakan contoh dari komunikasi interaksi antara guru dan siswa. Siswa dapat langsung mengemukakan pendapat, presentasi laporan serta memajangkan hasil kerja.
3. Interaksi

Gambar 5. Interaksi

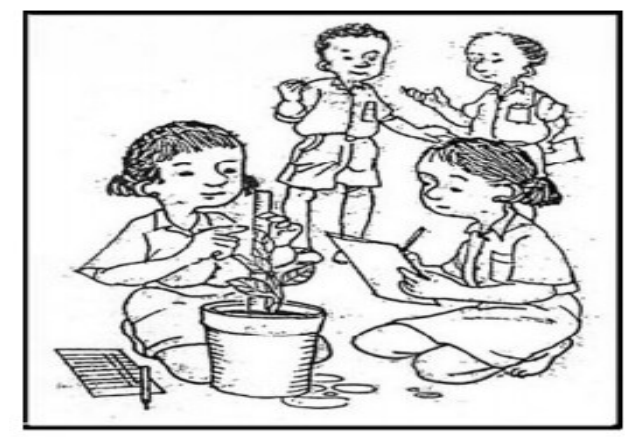

langsung guru dan siswa. Siswa dan guru dapat lakukan diskusi secara langsung, tanya jawab dan lempar pertanyaan.

\section{Refleksi}

Gambar 6. Refleksi

Pada gambar 5 merupakan refleksi.

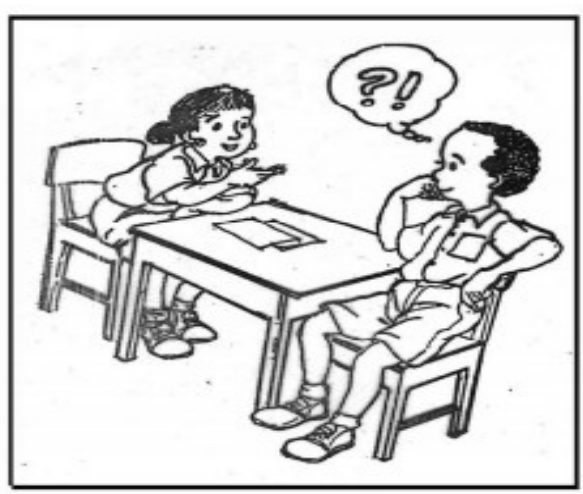

Refleksi adalah sebuah kegiatan yang dilakukan dalam proses belajar mengajar berupa penilaian tertulis maupun lisan (umumnya tulisan) oleh anak didik kepada guru/dosen, berisi ungkapan kesan, pesan, harapan serta kritikmembangun atas pembelajaran yang diterimanya [11]. Dalam hal ini refleksi adalah umpan balik dari pengetahuan yang telah didapatkan oleh siswa. Siswa diajak memikirkan kembali apa yang akan dibuat atau dikerjakan. Siswa diajak berpikir pola "WHY" artinya siswa diajak berpikir mengapa bisa ? Dan Apakah hal itu masih berlaku? 


\section{DAFTAR PUSTAKA}

[1] F. A. Huda, "Pengertian dan Langkah-langkah Model Pembelajaran PAKEM (Pembelajaran, Aktif, Kreatif, Efektif, Menyenangkan),” 2018. http://fatkhan.web.id/pengertian-danlangkah-langkah-model-pembelajaran-pakem-pembelajaran-aktif-kreatif-efektifmenyenangkan/\#: :text=PAKEM adalah sebuah model pembelajaran,belajar termasuk pemanfaatan lingkungan supaya (accessed Nov. 12, 2020).

[2] Sujiadi Sss, “Definisi Kognitif, Afektis dan Psikomotorik,” 2013. https://www.slideshare.net/sujiadisss/definisi-kognitif (accessed Nov. 12, 2020).

[3] Andhikados, “EMPAT PILAR PENDIDIKAN MENURUT UNESCO.” https://brainly.co.id/tugas/18405490 (accessed Nov. 12, 2020).

[4] A. A. S. B. Solo, "Praktek Bangun Datar dan Ruang dari Tusuk Gigi dan Play Doh SD Al Azhar Syifa Budi Solo bag 2,” 2016. https://www.youtube.com/watch?v=iOYRoDxH50c (accessed Nov. 12, 2020).

[5] N. Istiqomah, “RESUME BUKU PENGENALAN 4 PILAR PENDIDIKAN,” 2015. https://www.kompasiana.com/nuristiqomah15/55d88f6524afbd440913929c/resume-bukupengenalan-4-pilar-pendidikan\#: :text=Learning to be adalah belajar,harus bisa menjadi manusia seutuhnya.\&text=Learning to live together adalah belajar untuk hidup bersama. (accessed Nov. 12, 2020).

[6] E. Nurdiana, “Apakah Multiple Intelligence ?” https://www.kompasiana.com/www.angelgirl.com/54f6e837a33311ea608b4c61/apakahmultiple-intelligence (accessed Nov. 12, 2020).

[7] D. John, “Pengertian Empat Pilar Pendidikan.” https://www.silabus.web.id/pengertianempat-pilar-pendidikan/ (accessed Nov. 12, 2020).

[8] E. Wariati, "MODEL PEMBELAJARAN PAKEM.” https://www.academia.edu/7653996/MODEL_PEMBELAJARAN_PAKEM_Pakem (accessed Nov. 12, 2020).

[9] E. Zahara, "Penerapan Pendekatan Pembelajaran PAKEM dalam Meningkatkan Hasil Belajar Matematika Siswa Kelas IV SDN 002 Bagan Besar,” Prim. J. Pendidik. Guru Sekol. Dasar, vol. 5, no. 3, pp. 411-415, 2017.

[10] A. Ghufrom, “Pembelajaran PAKEM,” 2011. http://staffnew.uny.ac.id/upload/131782837/pengabdian/PEMBELAJARAN+PAKEM+.pdf (accessed Nov. 12, 2020).

[11] R. Dian, “Apa Pengertian Refleksi Dalam Dunia Pendidikan.” https://www.scribd.com/doc/313484019/Apa-Pengertian-Refleksi-Dalam-Dunia-Pendidikan (accessed Nov. 12, 2020). 